\title{
ケブラ一短繊維強化エポキシ樹脂の力学分散
}

\author{
三菱電機株式会社中央研究所 児玉峯一・古橋靖夫
}

\section{MECHANICAL DISPERSION OF SHORT KEVLAR FIBER-REINFORCED EPOXY RESIN}

\author{
By Minekazu Kodama and Yasuo Furuhashi \\ (Central Research Laboratory, Mitsubishi Electric Corporation, \\ Minamishimizu, Amagasaki, Hyogo)
}

\begin{abstract}
The dynamic viscoelastic properties of epoxy resin reinforced with short Kevlar fiber in randomplanar orientation were studied above room temperature. The composite reinforced with short $\mathrm{E}$ glass fiber in random-planar orientation was also studied for comparison purpose. Above the primary dispersion ( $\alpha$ ) temperature for the Kavlar reinforced composite, three additional dispersions $\left(\alpha^{\prime}, \alpha^{\prime \prime}\right.$ and $\alpha^{\prime \prime}$ ) are separately observed in the $\log E^{\prime \prime}$ vs. reciprocal absolute temperature curve. On the other hand, two additional dispersions ( $\alpha^{\prime}$ and $\alpha^{\prime}$ ) are observed above the $\alpha$ dispersion temperature for the $\mathrm{E}$ glass fiber reinforced composite. The $\alpha^{\prime \prime}$ and $\alpha^{*}$ dispersions of the Kevlar composite are considered to correspond to the $\alpha^{\prime}$ and $\alpha^{\prime \prime}$ dispersions of $\mathrm{E}$ glass fiber composite, respectively, for which the relaxation mechanisms are deduced in a previous paper $\left.{ }^{4}\right)$ The $\alpha^{\prime}$ dispersion of the Kevlar composite is considered to originate from the friction or slippage among the microfibrils of Kevlar fiber which are formed by the fibrillation or splitting of the fiber surface during the measurement of the dynamic viscoelastic properties.
\end{abstract}

(Received July 30, 1977)

\section{1. 緒言}

ケブラー緎維证低密度，高強度，高弹性を示し，複合 材料用强化材として注目をあずている。しかし，ケブラ 一繊維で強化された複合材料は曲げ强度，曲げ疲労強度 が小さいという尔を持つことも知られている゙。てれ はケブラー一織維の微細構造がのびきり分子銷に上り構成 されているために繊維軸と平行な面でスプリ，卜しやす いためである゙、名と考えられている。このスプリットは 複合体の破壞に近い状態で生じるととが認かられている。 钽少変形ではケブラー繊維の微細構造は変化しないかよ゙ うか在知る目的，挍上び，複合体に和ける强化林一マト

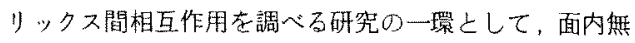
配向のケブラー短䄉維強化エポキシ樹脂硬化物の力学分 散を調べた。比較のために，力学分散現象がある程度明 らかにされているガラス短織維強化系の力学分散 ${ }^{4,5}$ も 調べた。然配向強化系の挙動をより明らかにする目的で

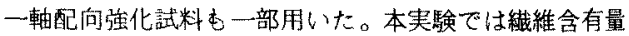
は比較的小さいとしろを選んだ。䋊維一マトリックス間 相互作用にもとつく効果を把握しやすくするためである。

\section{2. 実験方法}

\section{1 試 料}

表1に用いた試料を示した。試料記号 $\mathrm{K} ， \mathrm{G}$ はそれぞ れケブラ一繊維(デュポン社)，Eガラス織維(日東紀) で䖪化した屯のである。それぞれの繊維は $10 \mathrm{~mm}$ の長さ の6のを用いた。ケブラー䋐維はカミンリの羽で端面を 賃つけないように入念に切断した。マトリックス樹脂は ビスフェノールエポキシ樹脂エピコート815とイソフォ ロジアミンを 100:24の割合に混合したものを用いた。 $\mathrm{K}-1, \mathrm{~K}-2$ は面内無配向ケブラー絿維で强化したもの である。K-P．K-Vはを机ぞれ試料の長さ方向に平 行および垂直にケブラー瀻維を配列したものである。G $-1, G-2$ は面内無配向のEガラス繊維で強化したもの 
Table 1. Sample Preparation

\begin{tabular}{|c|c|c|c|c|}
\hline \multirow{2}{*}{ Code } & \multirow{2}{*}{$\begin{array}{c}\text { Matrix } \\
\text { (weight ratio) }\end{array}$} & \multicolumn{2}{|c|}{ Reinforcement $* * *$} & \multirow{2}{*}{$\begin{array}{l}\text { Cure } \\
\text { condition }\end{array}$} \\
\hline & & Material (length, mm) & Cont. $\%$ in vol. & \\
\hline $\begin{array}{l}\mathrm{K}-1 \\
\mathrm{~K}-2 \\
\mathrm{~K}-\mathrm{P} * \\
\mathrm{~K}-\mathrm{V}^{* *} \\
\mathrm{G}-1 \\
\mathrm{G}-2 \\
\mathrm{G}-\mathrm{P}^{*}\end{array}$ & $\begin{array}{l}\text { Epikote } 815 / \text { isophorone- } \\
\text { diamine }(100 / 24)\end{array}$ & $\left\{\begin{array}{l}\text { Kevlar-49 fiber }(10) \\
\text { E type glass fiber }(10)\end{array}\right.$ & $\begin{array}{r}8.0 \\
15.0 \\
12.0 \\
13.3 \\
8.0 \\
14.0 \\
12.7\end{array}$ & $\left\{\begin{array}{c}\left(100^{\circ} \mathrm{C}, 1 \mathrm{hr} .\right) \\
+ \\
\left(150^{\circ} \mathrm{C}, 3 \mathrm{hr} .\right)\end{array}\right.$ \\
\hline
\end{tabular}

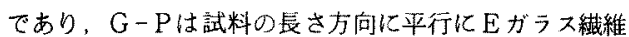
を配列したものである。図1亿複合体中の繊維の配列を 模式的に示した。複合体の作製は次のようにして行った。 $\mathrm{K}-1, \mathrm{~K}-2, \mathrm{G}-1, \mathrm{G}-2$ の場合はそれぞれの繊維 から面内無配向マット(バインダーとしてポリビニルア ルコールを用いた。マット中の含有量は約 3 \%)をまずつ くり，乙れ折要量のマトリックス樹脂を含浸媛，便化 させる方法を用いた。マットの作り方は次のように行っ た。10 mmの長さのそれぞれの緇維をポリビニルアル コールを含む大量の純水中に高速かくはんしながら分散

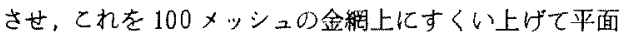
的に店げ，水切り後，金網からはずして，2枚のガラス 板の間にはさんで咸圧下 $(40 \mathrm{mmHg}) 100^{\circ} \mathrm{C} て ゙ ~ 16$ 時間 乾燥した。 $\mathrm{K}-\mathrm{P} . \mathrm{K}-\mathrm{V}, \mathrm{G}-\mathrm{P}$ は，㴗のある治具用 い、それぞれの織維を平行に並へ，その上からマトリッ クス樹脂在渢下，含浸させて作った。面内無配向マット

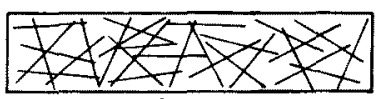

(a)

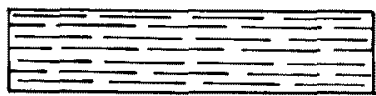

(b)

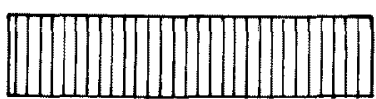

(c)

Fig. 1. Schematic representation of composites reinforced with randomly distributed fibers (a), with uniaxially aligned fibers in the direction of sample length (b), and with perpendicularly aligned fibers to the direction of sample length (c).
をつくる際に用いた䟝ビニルアルコールは，ここで用 いたようなマトリックス樹脂を含漫し，加熱すると，マ トリックス樹脂中に拡散，混合するここが考えられ，複 合体中での繊維關相互作用に重大な影響を及ぼすととは 無いと考えられる。

\section{2 測 定}

岩本製作所製粘弾性スペタトロメーターを用いて，策 純伸長变形による粘弾性の測定党行い，動的弾性率 $E^{\prime}$ ， 挰失弾性率 $E^{\prime \prime}$ 常温以上の温度域で求めた。

\section{4. 実験結果と考察}

\section{1 無配向繊維強化複合体の損失弾性率}

因 2 に $\mathrm{K}-1, \mathrm{G}-1$ の損失弾性率の温度依存性をマ卜 リックス樹脂の場合とあわせて示した。 $85^{\circ} \mathrm{C}$ 以上温度 域について示した。これ以下の温度域では各試料に特街 的な挙動は見られなか力た。図2から明らかなように

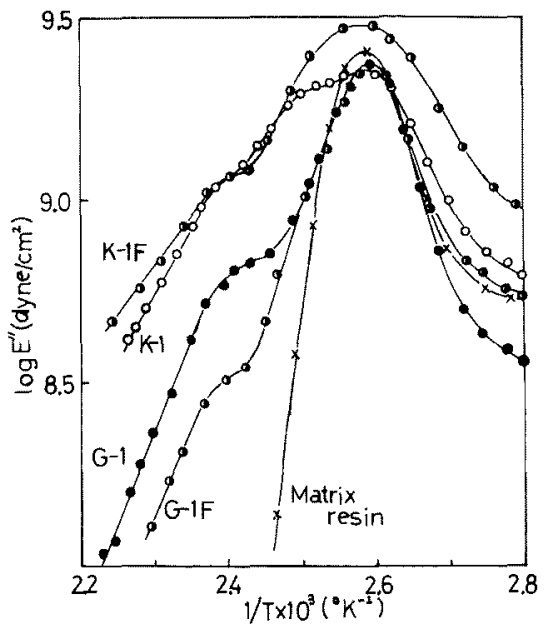

Fig. 2. Temperature dependence of loss modulus for $\mathrm{K}-1, \mathrm{G}-1, \mathrm{~K}-1 \mathrm{~F}$ and $\mathrm{G}-1 \mathrm{~F}(10 \mathrm{~Hz}$.). 
-1，G-1ともにマトリックス樹脂と同じ温度位置に主 分散 ( $(\alpha)$ 加あらわれる。G-1では既報 ${ }^{4,5)}$ のうに主 分散より高温側にもう一つの分散が局となって現われる。 K-10場合にはこれとにぼ同じ温度位䁂にあ分散か現 われるが、さらにもつ1つ0分散が両分散の中間城に生 しる。图 $20 K-1 F ， G-1 F$ は $-1 ， G-1 K$ 常温で 引張り疲労 (平均底力 $1 \mathrm{~kg} / \mathrm{mm}^{2}$, 応力振幅 $0.9 \mathrm{~kg} / \mathrm{mm}^{2}$,

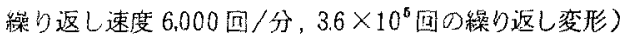
を与克たものである。

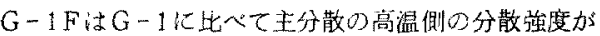
小さくなり，主分散より低温侧ではE゙は大きくなる。K -1Fでは $K-10$ 低温側の2つの分散肪合体して，1つ の大きな分散になるが，屯う1つの分散（最高温域の分 散は古まり大きな影暨は受计ない。

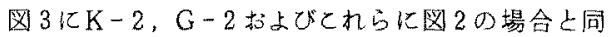
条件で波学を与えた試料 $\mathrm{K}-2 \mathrm{~F}, \mathrm{G}-2 \mathrm{~F}$ 損失弾性摔

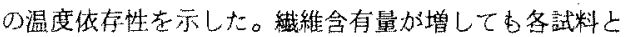

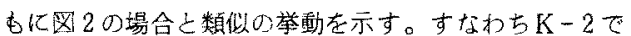
は3つ, G-2では 2 つ分散があらわれ，各分散の温 度位置は $K-1 ， G-10$ 場合上同しになり，波学を年え たことによる分散举動の変化李傾向としてはK-1，G－ 1の場合亡同じである。ただし，主分散以外の分散の大 きさは綫維含有量が増加する上大きくなり，なかでも， K試料の中間温度域の分散は䋐維含有量が增す之明瞭な ピークになるこよは特徴的である。

図 $4 \mathrm{kK}-1, \mathrm{~K}-2, \mathrm{G}-1, \mathrm{G}-2$ の動的弾性率 $E^{\prime}$ の温度依存性を示した。繊維含有量が等しいか，古るい はほよんど等しい $\mathrm{K}-1$ とG-1あるいは $\mathrm{K}-2$ よ $\mathrm{G}-2$ を

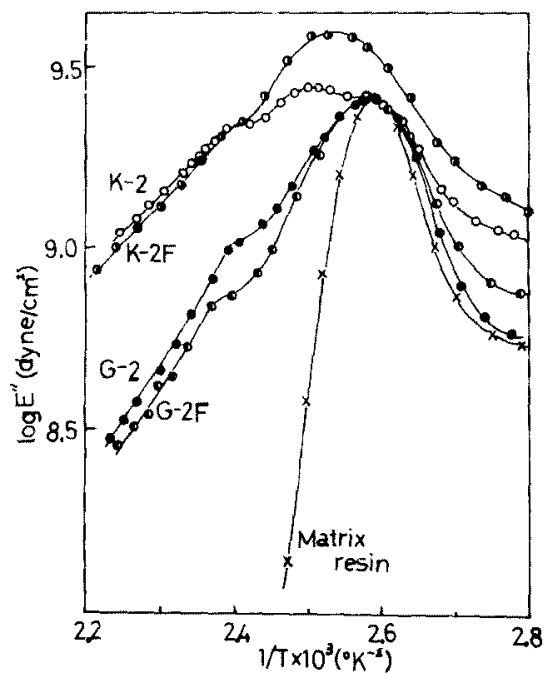

Fig. 3. Temperature dependence of loss modulus for $\mathrm{K}-2, \mathrm{G}-2, \mathrm{~K}-2 \mathrm{~F}$ and $\mathrm{G}-2 \mathrm{~F}(10 \mathrm{~Hz}$.).

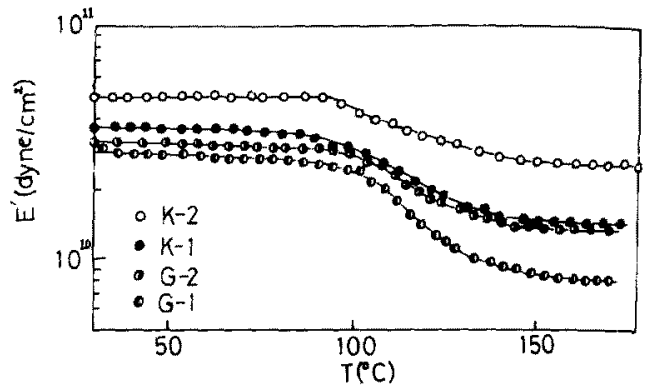

Fig. 4. Temperature dependence of storage modulus for $\mathrm{K}-1, \mathrm{G}-1, \mathrm{~K}-2$ and $\mathrm{G}-2(10 \mathrm{~Hz}$.).

在此較すると明らかなよう全温度域にわたってK試料

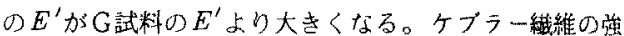

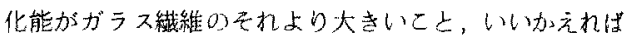

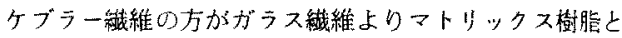
り相互作用が強いととを示していると考えられる。

\section{2 一軸配向緎維強化複合体の損失弹性率}

図 $5 k \mathrm{~K}-\mathrm{P}, \mathrm{K}-\mathrm{V}, \mathrm{G}-\mathrm{P} O$ 損失弹性率の温度伐存 性を示した。織維合有率がてれらのものに近い舆配向縺 維強化試料 $\mathrm{K}-2$ よG-2およびマトリックス樹脂の結 果も比較のため示した。 $\mathrm{K}-\mathrm{P}, \mathrm{K}-\mathrm{V}, \mathrm{G}-\mathrm{P}$ いずれ 委1つの分散し加生じない。 $K-V, G-P の$ 分散のピ 一ク温度位置はマトリックス樹脂のもの之同じになり， $\mathrm{K}-\mathrm{V}, \mathrm{G}-\mathrm{P}$ の分散曲線はを扎でれK-2，G-20主 分散域を中心しした筙用にほぼ限られる。それに対して

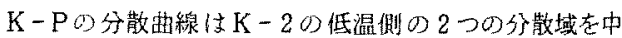
心とした籍用にはば限られる。すなわち，KーPでは見

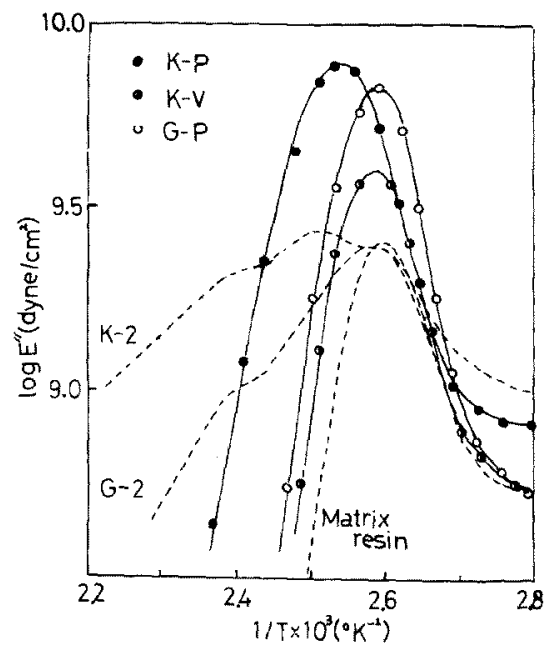

Fig. 5. Temperature dependence of loss modulus for K-P, K-V and G-P $(10 \mathrm{~Hz}$.). 
かけ上 1 つ0分散が観测されるが，乙れはK-20低潈 側の 2 つ分散に相当するものが分離し得ずに合体して 現われたものと見るこよもできよう。

\section{3 共存分散の分離}

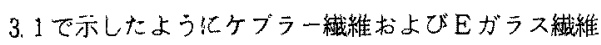
による無配向強化試料では，見かけ上，それぞれ2つ拉 よび1つ0分散が主分散之共存する。

既報 ${ }^{4,5)}$ のように無配问ガラス䋐維強化等硬化性樹脂 ではこのような $\log E^{\prime \prime}$ vs. 1/T曲線上の見加上2つ の分散は3つの緩和機構飞分離出来る。

そこで, $K-2, G-2, K-2 F, G-2 F$ 場合につ いて，既報の上うに河合の方法 ${ }^{6)}$ にしたがい，共存分散 を主分散から分離した。分離の操作は次の上うな3つ0 仮定にむとついて行った。）各縓和機構の間には粘弾 性関数における加成性が成立する，ii）各緩和機構にお いて独立に㵋度－時間換算則が成立する，iii）各緩和機 構の損失弾性率は次式のようなガウスタイプの対称関数 であらわされる。

$$
\log E^{\prime \prime}=A \exp \left[-C\left(\frac{1}{T}-\frac{1}{T_{0}}\right)^{2}\right]
$$

上式の $A, C, 1 / T_{0}$ はガウス関数を特徽つける数值であ り，Aは損失弾性率の極大値の対数值，Cは分散の鋭さ を示すパラメーター．1/T0は損失弾性率が極大值を示す

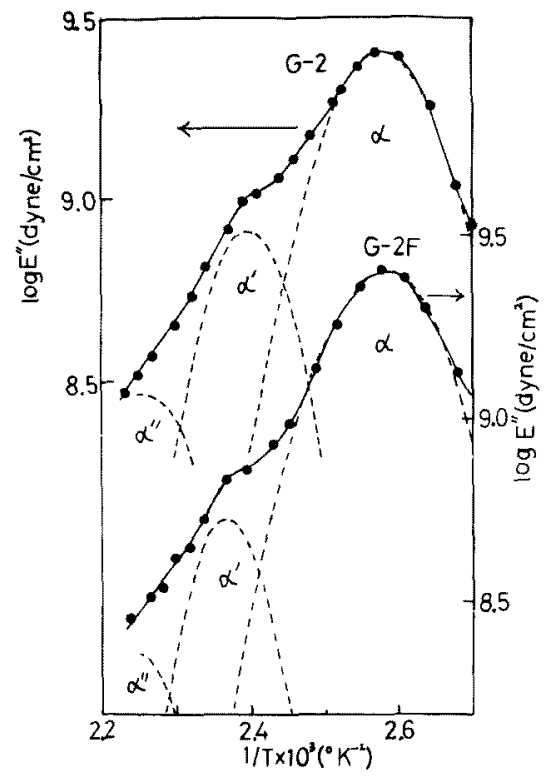

Fig. 6. Separation of additional dispersions via plot of $\log E^{\prime \prime}$ vs. $1 / T$ for $\mathrm{G}-2$ and $\mathrm{G}-2 \mathrm{~F}$. Broken curves are a Gaussian function to fit each dispersion.
絶対温度の逆数在示す。因6，7亿分離した結果を示し た。既跟 ${ }^{4,6)}$ の場合と同様にG-2では $3 つ($ (低鼬侧から $\alpha ， \alpha^{\prime}, \alpha^{\prime \prime}$ 上する)の分散に分離出来る。 $\mathrm{G}-2 \mathrm{~F}$ でも 3

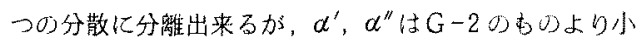
さくなる。

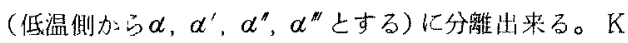
-2Fでは $\alpha$ と和に相当するもりが合体して $\alpha_{c}$ よかりり， $\alpha^{\prime \prime} ， \alpha^{\prime \prime}$ に相当する屯のは大きさを减少して残存する。 表 2 には各分散をあらわすガウス関数を特徴づける数值

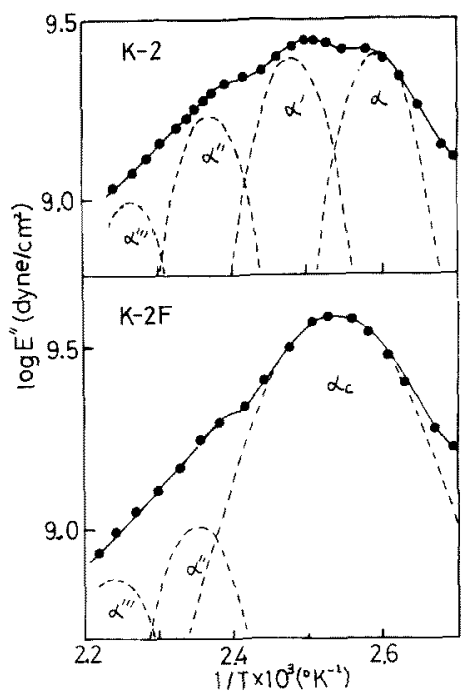

Fig. 7. Separation of additional dispersions via plot of $\log E^{\prime \prime}$ vs. $1 / T$ for $\mathrm{K}-2$ and $\mathrm{K}-2 \mathrm{~F}$. Broken curves are a Gaussian function to fit each dispersion.

Table 2. Constants Characterizing the Gaussian Functional Form of Each mechanism

\begin{tabular}{c|c|c|c|c}
\hline Code & Mechanism & $A$ & $C \times 10^{-6}$ & $1 / T_{0} \times 10^{3}$ \\
\hline \multirow{4}{*}{$\mathrm{G}-2$} & $\alpha$ & 9.41 & 3.7 & 2.58 \\
& $\alpha^{\prime}$ & 8.91 & 7.4 & 2.39 \\
& $\alpha^{\prime \prime}$ & 8.47 & 6.0 & 2.26 \\
\hline \multirow{4}{*}{$\mathrm{G}-2 \mathrm{~F}$} & $\alpha$ & 9.41 & 3.7 & 2.58 \\
& $\alpha^{\prime}$ & 8.73 & 8.7 & 2.37 \\
& $\alpha^{\prime \prime}$ & 8.36 & 7.0 & 2.24 \\
\hline \multirow{4}{*}{$\mathrm{K}-2$} & $\alpha$ & 9.40 & 9.2 & 2.60 \\
& $\alpha^{\prime}$ & 9.38 & 9.0 & 2.48 \\
& $\alpha^{\prime \prime}$ & 9.23 & 9.1 & 2.37 \\
& $\alpha^{\prime \prime \prime}$ & 9.00 & 17.4 & 2.27 \\
\hline \multirow{3}{*}{$\mathrm{K}-2 \mathrm{~F}$} & $\alpha_{c}$ & 9.59 & 2.3 & 2.54 \\
& $\alpha^{\prime \prime}$ & 9.01 & 7.7 & 2.36 \\
& $\alpha^{\prime \prime \prime}$ & 8.87 & 9.3 & 2.24 \\
\hline
\end{tabular}


を示した。

3.4 各分散の機構についての推定

既報 ${ }^{4,6)}$ のように無町向ガラス緎維强化熱硬化性樹脂 に現われる $\alpha^{\prime} ， \alpha^{\prime}$ 分散の機構は次のように考えられる : 図 8 に複合体中でのガラス纎維の交差を模式的に示した が，領域Aのような交差点近傍に含漫されたマトリック 又樹脂は瀻維の表面力場の影響を強く受けだ状態で硬化 し，領域 Bのマトリックス樹脂に比へて運動性が大きく

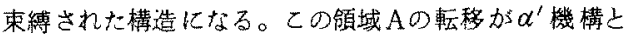

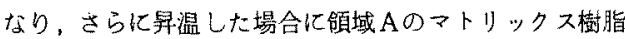
としの部分に接する繊維の間のまさつやすべりが生じる ようになり，これが機構となる。領域 $\mathrm{A}$ の割合に対 して領域 $\mathrm{A}$ 上接する緎維表面皘は比較的大きいので $\alpha^{\prime \prime}$ 機構が分唯し得るものと考えられる。

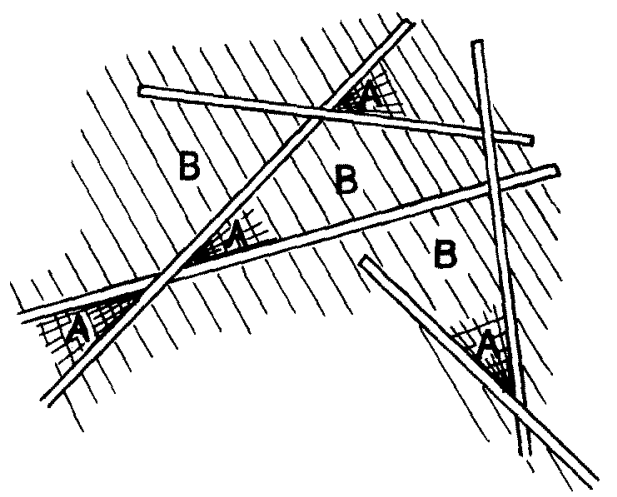

Fig. 8. Schematic representation of the intersections of glass fibers in composite.

$G-2 の \alpha^{\prime} ， \alpha^{\prime \prime}$ 分散もとのような機構にもとつくのの と考えて良い。さらに，分散のピーク温度位置がほぽ等 しいととと，疲学挙動加類似しているとと加ら，K-2

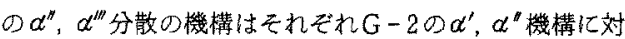
応するあのと考えられる。

$K-20 \alpha^{\prime}$ 分散の機構は，3.3で述へたように，岥労 によって $\alpha と \alpha^{\prime}$ が合体して $\alpha_{c}$ にるという事実加ら推 定される。G-20場合加らも明らかなようい分散は 疲労によっては全く変化しない。したがってK-2Fで 大きな $\alpha_{c}$ が生じるのは波労比って $\mathrm{K}-2 \omega \alpha^{\prime}$ が增大し

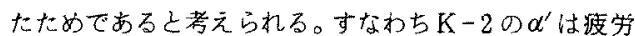
によって增大するような性格のあのである。

D. B.Eagles ら $ら^{7)}$ (各種熱可塑性樹脂中に埋め入んだ ケブラー瀻維の笚瀻維引抜き試験を行った。ポリカーボ ネート、ポリメタクリル酸メチル等に埋め込んだ場合の 界面せん断強度は大体 $1 \times 10^{8} \mathrm{dyne} / \mathrm{cm}^{2}$ 前後であり， 引抜き後のケプラー瀻維表面ではフィブリル化が生じて
いることを示している。本実験におりる疲学条件，試片 中の繊維含有率加概算すると，坡労時にケブラ一瀻維 が受け持つ忘力は，繊維の配向方向を考虑に入れない平 均的な值としては $1 \times 10^{7} \mathrm{dyne} / \mathrm{cm}^{2}$ 程度になる。本実験 の場合のケブラ一界面世ん断强度む $1 \times 10^{8} \mathrm{dyne} / \mathrm{cm}^{2}$ 程 度であると考えると疲労時のケブラ一繊維が受け持つ応 力は世九断強度の1/10程度になる。し加し静的強度の $1 / 10$ 程度の応力で $10^{\circ}$ 回のくり返し変形を与えれば,

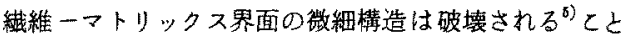

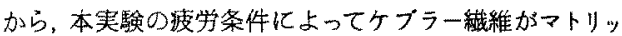
クス樹脂との界面付近でフィブリル化される可能性は十分 ある。とれらのととから，疲労による $K-2 の \alpha^{\prime} の$ 增加は ケブラー瀻維のフィブリル化の進行によりミクロフィブリ 儿間のまさつやすへりりが增加するためであると考えられる。

末波学試料 $(K-2) の \alpha^{\prime}$ あケブラ一㵶維に生じたミク

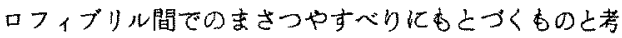
えら扎る。 $\alpha^{\prime}$ 分散が生じる温度域では因80領域Bは 皮革状態汃らゴム状態にあるが，領城Aはガラス状態で あると考えられる。したがって $\alpha^{\prime}$ 分散温度域では領域 Aが 束縛点となり，領域 Bの分子銷の long rangeな運動によ り，領域 Bと接したケブラー瀻維の末端付近からフィブリ 儿化が生じるすの上考えられる。ケブラー緎維切断時に受 けた㐫力のために緎維末端では剥離しやすい状態てなって いるこよが考えられ゙，ささらに，粘断性測定時に加えられる 応力 (繊維が受け持つ応力は平均的には $5 \times 10^{8} \mathrm{dyne} / \mathrm{cm}^{3}$ ) の胶果毛加わって，フィブリル化の可能性は大きくなろう。

3. 2 で述べた $K$ - VD場合には測定中にフィブリル化 が進行して屯瀻維の配列力向之粘弹性測定時の応力の方 向が直角なために $\alpha^{\prime}$ は生しないと考えられる。また， K-Pでは図 8 の領域Aの上うな束縛点が無いために と $\alpha^{\prime}$ が分離して生じ得ないあのと考えられる。

付記：本研觉の内容蜮維学会昭和 52 年年次大会 (於 東京，昭和 52 年 6 月 15 日)にて発表した。

\section{文献}

1）古田敏康、野口義男，松嶋正道；航技研報告，TR -413, May (1975)

2）矢吹和之。伊藤 弘，太田利彦; 緎学誌，31，T$524(1975)$.

3）矢收和之，伊藤 弘，太田利彦；䄉学誌，32，T55 (1976)

4) M. Kodama; J. Appl. Polym. Sci., 20, 2165 (1976).

5) M. Kodama; J. Appl. Polym. Sci., 20, 2853 (1976).

6）河合弘迪；「レオロジー入門」(岡小天編)，工業玨 查会, p.137 (1970).

7) D. B. Eagles, B. Blumentritt, S. L. Cooper; J. Appl. Polym. Sci., 20, 435 (1976). 